\title{
Analysis on the Overall Effects of Brexit
}

\author{
Jiaqi Gao
}

\author{
${ }^{I}$ Meihua School, Suzhou, China, 215345 \\ ${ }^{*}$ Corresponding author. Email: gloriagao0904@gmail.com
}

\begin{abstract}
Any member state of the European Union can have a right to leave the union based on the withdrawal agreement presented in Article 50 of the Treaty of Lisbon. The United Kingdom in 2016 successfully held a referendum in 2016 to leave the European Union, which came to be popularly known as Brexit. Small and Medium-sized Enteprises form the background of the UK's economy. Over 90\% of the 57 million businesses in the UK as of 2017 are SMEs. With the Brexit underway, some of the SME owner fear that the imminent changes may drastically affect the operation of SMEs. Although this may be true, the Mc Kinsey Co advises SMEs on way to overcome challenges presents by Brexit and how to leverage the opportunities Brexit presents. Some of the areas that may be negatively affected by Brexit imposition of export tax on UK goods. Brexit will likely have a significant impact on businesses in both the EU and the UK. However, most academic literature only focus on the effect of Brexit on large companies. This paper therefore outlines in detail the Brexit process and the impact of the withdrawal on small and medium size enterprises (SMEs). This paper seeks to explore two questions; the effect of Brexit on SMEs and what SMEs should to do overcome the negative effects on Brexit.
\end{abstract}

Keywords: Brexit, Article 50 of the Treaty of Lisbon, Effect of the Brexit, United Kingdom, SME (Small and Medium Enterprises)

\section{INTRODUCTION}

BREXIT is the withdrawal of the United Kingdom (UK) from the European Union (EU). The UK first joined the EU in 1973 when it was still known as The European Community (EC) with Edward Heath as Prime Minister under the Conservative Party. Joining the EC was endorsed by a referendum in 1975. Those skeptical about joining the EC advocated for the withdrawal of the UK while those supporting advocated for the continuous membership. Under Article 50 of the Lisbon Treaty gives any member country the liberty to quit and outlining the procedure for quitting. The treaty also gives the country in question a two-year period to negotiate on the exit deal after which, the leaving state finalizes on the withdrawal deal. What follows is an outline of how the leaving state will relate with the EU in future endeavors. The Lisbon Treaty is divided into two concerning withdrawal of member states. First, declaring that a member state can leave the EU. Second, the EU determines the withdrawal process and how to manage the withdrawal. Since its establishment, only three states have withdrawn from the EU. The last two countries still retain the title of Overseas Countries and Territories of the European Union (OTC), meaning they can cooperate with the EU on certain issues without being members of the EU [8]. The reason the three regions left the EU was disagreements on fishing policies and the control of Greenland fishing resources as they remain outside EU maritime control. The research theme of this article is to explore the effect of Brexit on SME's and the solutions available to SME's to overcome the negative effects of Brexit. The specific problem that will be explored is the specific challenges that have faced SME's in terms of financing, labor challenges and in the supply chain segments. Scholarly case studies and literature review is the reseach method used to shed light on the issue addressed in the paper. This research is significant as it will provide key insights into how Brexit has affected SME's in the country and how these SME's can negate the negative effects of the SME. Additionally the research will provide further room for analysis on the effects of Brexit on the overall economy and the available solutions to the SME's during the course of Brexit. The paper will also provide knowledge on new opportunities that have emerged as a result of Brexit and this is important for the future of the economy. 


\section{PROCESS OF BREXIT}

The first draft of the BREXIT withdrawal agreement stood at 599 pages. It outlines how the UK is set to leave the EU. In the outline it covers how much money the UK owes the EU (this stands at about GBP 39 billion). The draft also outlines what will happen to UK citizens leaving in EU member states and the EU citizens leaving in the UK. Finally, the draft provides procedures of avoiding the emergence of the North Ireland border after quitting the EU. The BREXIT idea began in 2016 after the Brits voted for the withdrawal from the EU in a Referendum. The voter turnout of the referendum was $71.8 \%$ with over 33 million people voting. Over $50 \%$ of the voters voted in favour of leaving the EU. The UK Prime Minister at the time David Cameron resigned following the results of the referendum because he did not agree with the idea of the UK leaving the EU [7]. However, he respected the will of the majority to leave the EU.

As any member of the European Union, the UK contributes to the EU budget. In return, the UK also receives funding from the EU for agricultural, social and several economic and developmental projects which improve the UK's competitiveness [7]. For instance in 2017, the UK made contributions of GBP 13 billion. In return, the UK received GBP 4.1 billion in form of public receipts from the UK making the net contribution of the UK to the EU was about GBP 8.1 billion.

Despite the referendum being legally non-binding, the government at the time had to implement the will of the people. As such, the government began the official process of withdrawing from the EU on 29 March 2017. Based Article 50 of the Lisbon Treaty, the UK had until 29 March 2019 to complete their withdrawal when the two-year grace period would expire. However, on 20 March 2017, Theresa May, the UK Prime Minister at the time wrote a letter to the president of the EU asking for and extension. The European Council accepted the extension on two conditions. First, the British Members of Parliament had to approve the withdrawal before 29 March 2019. Second, if Members of Parliament fail to approve the withdrawal, then the UK had until 12 April to provide the European Council with an exit strategy otherwise the UK would leave the EU without a deal. The members of parliament approved the withdrawal before 29 March 2019 with led to the UK officially leaving the EU on 31 January 2020 [10]. The paper here in intent to determine the effect of BREXIT on Small and medium size enterprises (SMEs) in the UK and the EU.

\section{EFFECT OF BREXIT ON UK SMES}

Most academic resources and the media emphasize on the impact of Brexit on large companies. As such, there is little information on the effect of Brexit on
SMEs. Although large companies make huge profits and positively impact the economy of UK, SMEs are the backbone of UK's economy. They provide jobs, significantly contribute to growth and innovation in an era of economic volatility. As of 2017, SMEs made about $99 \%$ of all the 5.7 million businesses in the UK, provided over $70 \%$ of private sector employment and accounted for $73 \%$ of all job creations. SMEs also created about 2 million jobs between 2010 and 2017, meaning the way SME respond to Brexit has a huge influence on UK's economy.

According to a report on UK SMEs by Dan \& Bradstreet, titled Brexit and beyond, the UK economy is still within the top ten most competitive economies in the world based on the rankings of the World Economic Forum. However, this is not assured after Brexit. The sustainability of SMEs is critical to UK's future especially in time of uncertain and sudden change as Brexit. As such it is important that the UK understands the position of SMEs, their environment of operation and the challenges and opportunities that lie beyond Brexit. The following are the effects of Brexit on SMEs in the UK and the EU.

\subsection{Import Taxes on Small businesses}

After Brexit, the UK parliament has for the first time passed a law that will impose value added tax on all goods imported from EU regions into the UK. The new law will affect over 100,000 small businesses in the UK. For small business owners who import good from the EU will have to seek new suppliers either within the UK or out of the EU as a way of reducing cost of trade. Similarly, the law could be problematic to multinational retailers and major importers in the UK because the value added tax is passed through the supply chain during importation from the EU. By 2020, the VAT cost will trickle down to small businesses who will have to pay more to get their goods from EU suppliers [6]. The tax will increase the cost of doing business, which creates an unfavorable business environment for SMEs, which support the majority of the population.

Conversely, if SMEs are constantly growing and are making substantial profits, then the paying the VAT may not be a concern. This may be possible in future as SMEs in the UK seek for new trade relations with promising countries such as China and the United States, which are more advanced economies than most EU member states.

\subsection{Post Brexit SME Funding}

Before the UK left the EU, the EU provided fundings through the European Investment Fund (EIF). The EIF remitted billions of pounds into the UK economy since 1994. The funding helped fund and spark innovation among SMEs. The EIF provided the 
financing through banks and the banks issue the money to SMEs through loans. With Brexit, UK SMEs will not enjoy the benefits of this funding. Consequently, this is likely to have a significant impact on UK's economy because several SMEs will not receive funding [4]. Due to lack of funding to develop businesses, the tax revenue of UK will likely reduce leading to deficits. Most new companies in the UK will receive funding through crowdsourcing for initial investment.

\subsection{Expanding to International Markets}

Despite the negative impacts of Brexit on SMEs in UK, it also provides some major opportunities for SMEs. As mentioned earlier, Brexit will cause UK SMEs to find opportunities in international markets. In the international market, goods and services are affordable due to the fluctuations of the exchange rates that Brexit has had on the UK. Due to the improved exchange rates, UK SMEs can export their goods and service abroad at competitive prices. Additionally, Brexit will open trade opportunities with China, the US and Japan. Consequently, this will give SMEs an opportunity to expand to international markets which hence reaching new customers [10]. To gain more from such an opportunity, SME owners can improve their ecommerce presence and platforms for ease of doing business with international customers. That is, customers can log into the SME websites and purchase goods online.

\subsection{Supply Chain}

A major disruption of goods and service between the $\mathrm{UK}$ and EU was one of the most anticipated effects of Brexit. This change is change is likely to continue through 2021. Due to the new trend, SMEs will find it difficult to fulfill customer orders. However, to overcome this challenge, most SMEs responded by increasing stock of goods while tariff-free trade between EU and UK was in place. Brexit will continue affecting SMEs within both the UK and the EU. For UK SMEs to continue trading across borders, they must maintain good relationships with their EU suppliers by being transparent in their trade practices. For businesses which only transact business within the UK, one may thing they may not be affected by Brexit. However, this is not true because according to analysts, Brexit could lead to a $6.7 \%$ decrease in GDP in the UK in the next 10 to 15 years. Such an economic shock will negatively affect customers by reducing their purchasing power [3]. With reduction in purchasing poor, local SMEs will record low sales revenues.

As mentioned earlier, Brexit could pose opportunities such as expanding to international markets out of the EU and accessing more customers with high spending habits. Furthermore, according to McKinsey Global Growth Compass report, predicts that emerging markets such as Brazil, India and South Africa could account for about half of spending in 2020 and subsequent years. Therefore, UK SMEs could seek for market for their goods in these emerging economies to gain more from international business. Another opportunity for UK SMEs is the increase of international sales by UK companies in weeks following the referendum vote. This was due to the decrease in the pound s exchange rates which made UK goods cheap in the international market [9]. Similarly, SMEs could tap into this opportunity to increase sales

\subsection{Workforce}

With the full implementation of Brexit, the freedom of movement between the UK and EU ceased as of January 1, 2021. For European Economic Area (EEA) citizens who were in UK before, can continue their stay provided that they apply for settle or pre-settled status. This would be a good gesture for non UK citizens running businesses in the UK. Conversely, the restriction of movement is may have negative effects on UK SMEs because most of them depended on skilled EU migrants due to their competitive skills and low labour costs. In the post-Brexit era, both EU an non-EU migrants will be subject to the new immigration laws which will scrutinize both migrants according to the point based system for visa eligibility. For an immigrant's visa to be considered eligible to work in the UK, they must receive an approval from the employer [1]. This action accounts for fifty points. However, one requires seventy points for visa eligibility. Hence, the other twenty points are determined by factors such as level of education.

The restriction of movement in the new post-Brexit immigration system will lead to a temporary shortage in the workforce within the UK. This is because the UK has already experienced a reduction of more than $70 \%$ in EU migration since 2016 during and after the Brexit referendum. Due to the reduction in migration into the UK, the UK has a shrinking and ageing workforce [1]. However, SMEs can overcome this challenge by retraining or re-skilling available workers then placing then in long-term project to hone their practical skills.

\section{SOLUTIONS TO THE NEGATIVE EFFECTS OF BREXIT}

According to Dan \& Bradstreet (2018), businesses were showing a $19 \%$ reduction in confidence in 2018 during the implementation of the Brexit changes in the UK [5]. The lack of confidence still exists because of the fear of uncertainty of what could be the long term effect of Brexit on SMEs in the UK. Some businesses are considering leaving the UK and venture into other markets. However, 58\% of SME owners are optimistic that business will improve in the next five years if SMEs leverage the advantages presented by post-Brexit. 
In support of an optimistic Post-Brexit future for UK SMEs, the McKinsey Company in its 2019 study urges businesses to stop waiting for the uncertainties of Brexit but rather act to mitigate the challenges by leveraging opportunities. The opportunities that exist are those of in the service and digital sectors. The company also encourages UK businesses to revamp their supply chains to take advantage of digital technology and emerging markets as a way of overcoming the challenges posed by the post-Brexit period. The service sector is the best opportunity UK businesses can cease given the global market for traded services grows by more than $60 \%$ faster than the traded goods market. The services sub-sectors growing two to three times faster are IT, telecommunications and business services. Therefore, according to the McKinsey Company if UK SMEs invest in the services industry, they are likely to overcome the challenges presented by Brexit. For SMEs involved in the export business to gain full potential, the McKinsey Company recommends that such company's should focus on three interests. First, exporters should focus on growth, quick delivery to market, and closeness to customers. Because of the restrictions presented by Brexit, these businesses should focus their energy on shifting east towards China and west towards the United States. For instance, in the next 15 years or less the working age consumers in China are likely to increase by an additional 100 million people. This increase provide ready market for goods and services. Additionally, due to the ready market in advanced economies such as China, companies need to develop customer-centered models to succeeding in selling their goods and services [2]. For instance, companies need to give managers the authority to make quick decisions that will assure boost in sales.

Second, UK SMEs need to leverage the use of digital technology to make supply chains efficient and effective. These businesses can do this by capturing personal customer data. Through this, companies can improve their demand and sales forecasting by almost $90 \%$, which will significantly maximize customer satisfaction while minimizing the cost of sales lost. Accurate forecasting can also reduce the logistical cost by more than 30\%. Companies should employ technologies such as 3D printing, automation and capacity sharing platforms to further reduce logistic costs [10]. These technologies also ensure the delivery of better quality goods that those manually produced.

Finally, given that the business environment is rapidly changing, SMEs in the UK need to improve their agility beyond supply chain efficiency, customer proximity and digitization. By focusing on other factors that could lead to business improvement, businesses are likely to report improved financial performance [10]. Overall, the future of UK's economy may be uncertain during the initial stages of Brexit, however, by using the positives and the negatives of Brexit to attract new customers and create new business opportunities for SMEs will ensure SMEs owners and the people they support thrive.

\section{CONCLUSION}

The EU is one of the largest economies in the would which offers several benefits to its members. However, with Brexit underway, the UK SMEs will ensure challenges that may hinder their growth. The paper has highlighted the changes that have been brought about by Brexit. UK SMEs are likely to be adversely affected with Brexit in four ways. First, import taxation for small businesses, lack of funding from the EU to boost small businesses, restriction of movement of workers and disruption of the supply chain due to taxation. Despite the negative effects of Brexit to SMEs, Consequentially, this paper is significant as it has highlighted the areas that were affected by Brexit with respect to SME's and provided implementable solutions to these challenges on SME's. Brexit will give small businesses an opportunity to expand to other large markets such as China and the United States.

As a way of mitigating post Brexit challenges, SMEs should invest more on digital technologies to ensure the efficiency of the supply chain. For instance, by investing in ecommerce, SMEs will improve the ease of conducting business with international customers. The paper has however several deficiencies in that it does not provide a policy framewok and legal solutions that can help the SME's come up with ways to reduce the challenges faced. Additionally there is room for more solutions that can cut across a variety of industries that have been affected by Brexit especially in brick and motor industries. Futur areas of research are on how SME's affected by Brexit can improve productivity, reduce uncertainties and promote growth in a post Brexit world.

\section{AUTHORS' CONTRIBUTIONS}

This paper is independently completed by Jiaqi Gao.

\section{ACKNOWLEDGMENTS}

Developing this paper could not be possible without the help of a few people from my social and professional circle. First, I thank family members and friends for the support they have given me throughout my studies both financially and emotionally hence enabling me develop this thesis. I would also like to thank my teachers and colleagues in school for the guidance and provision of information to write the thesis. 


\section{REFERENCES}

[1] Brown, R., Kalafsky, R. V., Mawson, S., \& Davies, L. Shocks, uncertainty and regional resilience: The case of Brexit and Scottish SMEs. (J) Local Economy: The Journal of the Local Economy Policy Unit, vol 35(7), (2020), 655-675. https://doi.org/10.1177/0269094220979261.

[2] Brown, R., Liiares-Zegarra, J. M., \& Wilson, J. O. S. What Happens If the Rules Change? The Impact of Brexit on the Future Strategic Intentions of UK SMEs. (J) SSRN Electronic Journal. (2018). https://doi.org/10.2139/ssrn.3066614.

[3] Brown, R., Liñares-Zegarra, J., \& Wilson, J. O. S. The (potential) impact of Brexit on UK SMEs: regional evidence and public policy implications. (J) Regional Studies, 53(5), (2019), 761-770. https://doi.org/10.1080/00343404.2019.1597267.

[4] Burden, L. Brexit Will Ruin More U.K. Small Businesses, Economist Warns. (N) Bloomberg.com. April 15, 2021. https://www.bloomberg.com/news/articles/202104-15/brexit-will-ruin-more-u-k-small-businesseseconomists-warns.

[5] Dun \& Bradstreet. Implications of Brexit. (N) Ask.dnb.co.uk. 2018. https://ask.dnb.co.uk/help/about-dnb/implicationsbrexit.

[6] Howell, D. Small Business Owners: What Brexit Means To You. (N) Forbes. January, 2021. https://www.forbes.com/sites/davidhowell1/2021/0 1/31/small-business-owners-what-brexit-means-toyou/?sh=50ddad 413589 .

[7] Hunt, A., \& Wheeler, B. Brexit: All you need to know about the UK leaving the EU. (N) BBC News. December 2020. https://www.bbc.com/news/uk-politics-32810887.

[8] Institute for Government.. Brexit Brief: Article 50. (N) The Institute for Government. October 17, 2016.

https://www.instituteforgovernment.org.uk/brexit/b rexit-brief-article-50.

[9] McKinsey Company.. Productivity: The route to Brexit success. McKinsey \& Company. (N). 2018. https://www.mckinsey.com/featuredinsights/europe/productivity-the-route-to-brexitsuccess.

[10] Szabó, A.. The Impact of the Brexit on the UK SMEs. (J) ResearchGate. (2019) https://www.researchgate.net/publication/3352590 66_THE_IMPACT_OF_THE_BREXIT_ON_THE _UK_SMEs. 